\title{
Diurnal activity patterns of walia ibex (Capra walie) in Simien Mountains National Park, Ethiopia
}

\author{
Dessalegn Ejigu (Corresponding Author) \\ Department of Biology, College of Science, Bahir Dar University, Ethiopia. \\ E-mail: dessalegn_ejigu@yahoo.com
}

Afework Bekele

Deprtment of Zoological Sciences, Addis Ababa University, Ethiopia.

E-mail: afeworksimegn@gmail.com

Larkin Powell

School of Natural Resources, University of Nebraska-Lincoln, USA.

E-mail: 1powell3@unl.edu

Received: April 10, 2020 Accepted: May 5, 2020

doi:10.5296/jbls.v11i2.17049 URL: https://doi.org/10.5296/jbls.v11i2.17049

\begin{abstract}
Walia ibex (Capra walie) is an endangered and endemic species restricted to Simien Mountains National Park (SMNP), Ethiopia. Data on activity patterns of walia ibex were collected during October 2009 to November 2011, and the main objective of the research was to determine diurnal activity patterns of walia ibex in Simien Mountains National Park in order to design sound conservation strategies for the species. Scan sampling method was used for data collection on diurnal activity patterns of walia ibex. Diurnal activity patterns in walia ibex were bimodal, in which they were active before and after noon. They rest in shade on rocks and cliffs during the mid-day to protect themselves from hot sun and predators. Activity patterns of walia ibex during the day showed statistically significant differences $\left(\mathrm{F}_{7,18228}=\right.$ $82.09, \mathrm{df}=7, \mathrm{p}<0.01)$. Feeding showed significant differences compared to moving, standing, resting, socializing, and other activities $(\mathrm{p}<0.05)$. Diurnal activity records in the walia ibex population during the wet and the dry seasons showed that time spent feeding was the highest and vigilance was the lowest. Knowledge of the pattern of this behavior can especially be useful to design conservation planning as successful reproduction in the population may be threatened by anthropogenic disturbances. Thus, information about the diurnal activity
\end{abstract}


patterns of walia ibex is essential for conservation planning of the endemic and endangered walia ibex in its natural habitats.

Keywords: diurnal activity patterns, scan sampling, Simien Mountains National Park, vigilance

\section{Introduction}

Walia ibex (Capra walie Rüppell, 1835) is an endemic and endangered species which has been occurred only in Simien Mountains National Park (SMNP). Similar to other large herbivores, Capra species are crepuscular and show a diurnal activity pattern of feeding and moving (Hess, 2002). Dunbar (1978) reported that walia ibex rest in shade on rocks and cliffs during the mid-day to protect themselves from hot sun and predators.

Walia ibex have a polygynous mating system, in which the dominant male has a long-term, exclusive relationship with more than one female (Dunbar \& Dunbar, 1981; Nievergelt, 1981). Walia ibex can breed throughout the year with no specific seasonality, which makes it distinct from other ibex species such as the Nubian ibex in which breeding behavior is largely seasonal (Nievergelt, 1981; Massicot, 2001). However, peak sexual activity in walia ibex could also be observed from March to May (Dunbar \& Dunbar, 1981; Nievergelt, 1981). As the rut approaches, adult males join a herd of females and compete to mate with the estrus female.

Walia ibex in SMNP have modified their range in response to human activity and associated livestock (Ejigu et al., 2015), and these disturbances have potential to influence their activity and normal movement patterns (Beale \& Monaghan, 2004). Anthropogenic disturbance can cause severe alterations on species behavior and could influence on their physiology, population dynamics and ecology (Krausman \& Morrison, 2003).

Males and females usually live separately and differ in their habitat utilization in many social ungulate species. In Iberian ibex, for example, lactating females prefer safer habitats for their kids (Accevedo \& Cassinello, 2009). Differences in forage digestion efficiencies between males and females may cause males to adapt better in nutritionally poor habitats than females. Moreover, variation in activity time budgets between males and females could also contribute to segregation to different habitats outside their breeding season (Ruckstuhl \& Neuhaus, 2002).

Conservation planning for species of concern requires information on their diurnal activity patterns. Thus, the main objective of this research was to study diurnal activity patterns of walia ibex to design appropriate strategies to the conservation of the species in the area. Hence, differences in activity patterns of walia ibex was assessed from October 2009 to November 2011 for ten days every other month during the wet and the dry seasons to fill information gaps for this species.

\section{Materials and Methods}

\subsection{Description of the Study Area}

The present study was carried out in Simien Mountains National Park, which is located in the 


\section{Macrothink

Amhara National Regional State of Ethiopia in the North Gondar Administrative Zone

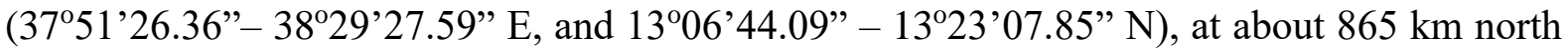
of Addis Ababa and $132 \mathrm{~km}$ northeast of Gondar town. Simien Mountains National Park includes broad undulating plateaux and the highest mountain of Ethiopia, Ras Dejen (Puff \& Nemomissa, 2005). It is an area of highest peak with unique land features in the Horn of Africa. The mountains symbolize an area of the extreme Ethiopian highlands (Hurni \& Ludi, 2000). Prior to the 1960s, the area was regarded as a royal hunting ground (Falch \& Keiner, 2000). During its establishment, SMNP was the smallest park in the country with an area of $136 \mathrm{~km}^{2}$ (Hurni \& Ludi, 2000). However, at present, the park's total area is $412 \mathrm{~km}^{2}$ (Anonymous, 2009) (Fig. 1).

The main rainy season in SMNP lasts from the end of June to September while the dry season covers from December to April. Annual rainfall in the park varies from $1000 \mathrm{~mm}$ in the lowlands to $1500 \mathrm{~mm}$ in the highlands (Hurni \& Ludi, 2000). Ground frost commonly occurs at night during the dry season especially in February and April. The mean annual temperature at Gich is $7.7^{\circ} \mathrm{C}$ (Hurni, 1982), however the area experiences night temperature variations ranging from $+2^{\circ} \mathrm{C}$ to $-10^{\circ} \mathrm{C}$. The ten year $(2000-2009)$ mean annual minimum and maximum temperature data were $8.7^{\circ} \mathrm{C}$ and $20^{\circ} \mathrm{C}$, respectively. As a result, variations in diurnal temperature far exceed seasonal variation, due to Ethiopia's proximity to the equator (Nievergelt, 1990).

The unique flora and fauna and its remarkable landscape make the park a natural priority for conservation and centre of endemism in East Africa (Hurni \& Ludi, 2000). The floral and faunal diversities and its unique landscape make the park a natural priority at regional, national and international levels (Hurni \& Ludi, 2000; Puff \& Nemomissa, 2001; Anonymous, 2009). According to Puff \& Nemomissa (2001), approximately 550 taxa of flowering plants grouped into over 95 families and 319 genera are known from Simien Mountains. It mainly consists of a mixture of Afro-alpine woods, heath forest, high mountain vegetation, montane savannah and montane moorland (Hurni \& Ludi, 2000; Ejigu, 2013). 


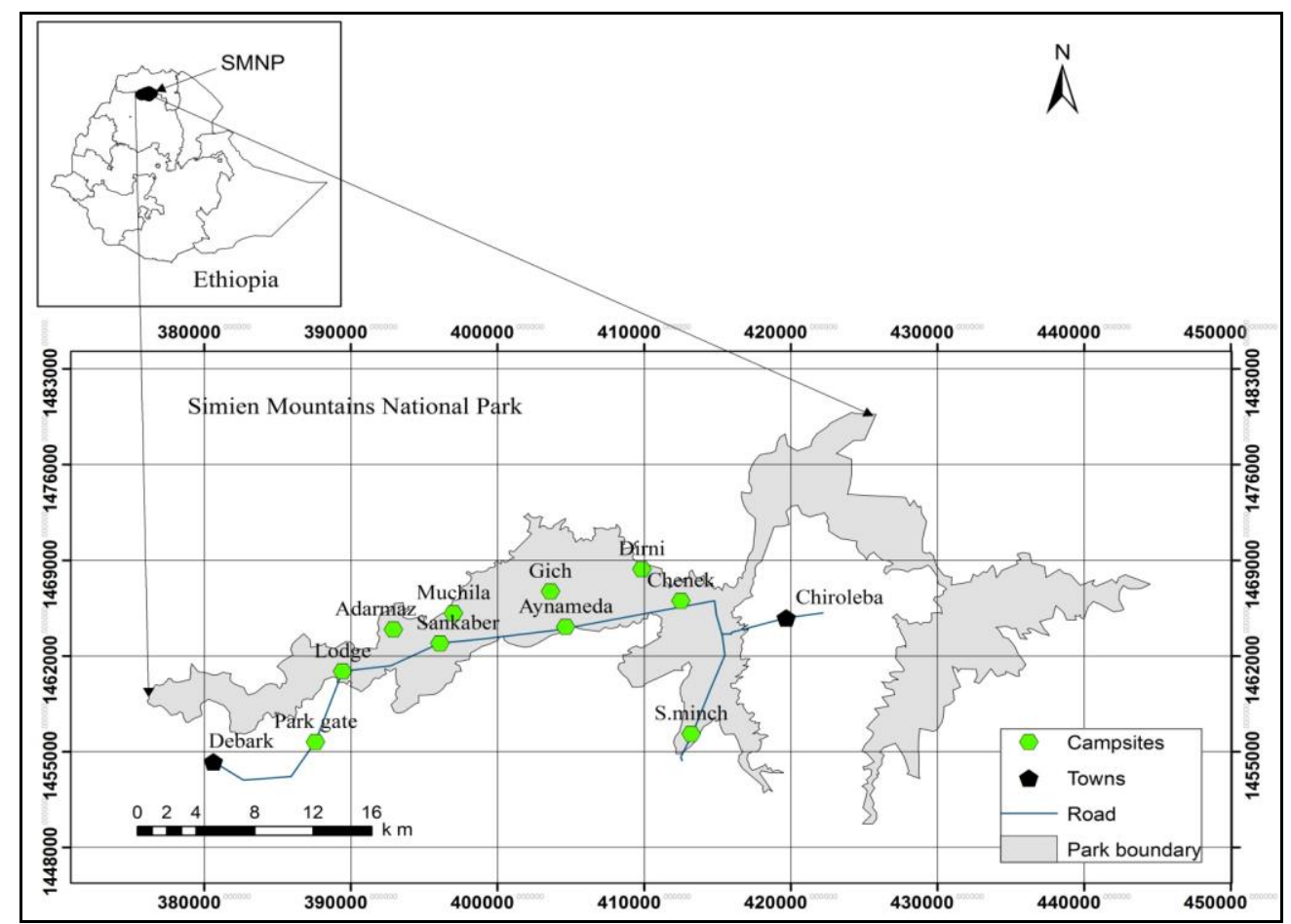

Figure 1. Location map of Simien Mountains National Park within Ethiopia

\subsection{Methods}

Based on a population projection model of Ejigu (2013) the current population size of walia ibex in the SMNP might be over 975 individuals. Diurnal activity patterns of walia ibex were recorded using scan sampling following Altman (1974). Activities such as foraging, moving, standing, resting, socializing, vigilance, rutting behavior and other activities (such as urination, defecation, drinking, suckling and licking) were used to study the behaviors of walia ibex. Activities which were sustained for three seconds were considered to avoid bias in sampling predominant behaviors (Bocian, 1997). Time spent on different activities was recorded to allow the construction of activity time budgets by time of day and for wet and dry seasons.

During each scan sampling period, the number of individuals seen, age, sex and activity patterns were recorded. Habitat characteristics were also recorded in a $10 \mathrm{~m}$ radius of the herd under observation (Vinod \& Sathyakumar, 1999). Activities were categorized as feeding on ground (grazing) or feeding above ground (browsing) including manipulating and processing the food in the mouth as adopted by Mobaek et al. (2005). Moving as an activity was recorded when the animal was taking more than two steps without feeding (Apio \& Wronski, 2005). Standing was recorded when the animal was at its standing position without watching the surroundings. Resting was recorded when the individual was lying down on the ground. Rutting was recorded when adult walia individuals were engaged in the rut. Vigilance was considered when the animal was standing with its head raised and looking carefully the surroundings. Defecation and urination were considered when the faeces, and urine were, respectively discharged from the body (Senft et al., 1987; Shorrocks \& Cokayne, 2005; 


\section{Macrothink}

Hochman \& Kotler, 2006). Observations were conducted from a distance of less than $100 \mathrm{~m}$ following Belovsky \& Slade (1986).

Chi-square $\left(\chi^{2}\right)$ tests were used to describe the differences in time spent in activities between age and sex classes. One-way ANOVA with a Tukey multiple comparison test was used to compare differences in diurnal activities during the wet and dry seasons.

\section{Results}

A total of 18, 236 activities of walia ibex were recorded during the whole study period; $51.6 \%(9,407)$ were recorded during the wet season, and $48.4 \%(8,829)$ during the dry season. The activity most often observed was feeding ( $40.5 \%$ of observations, $n=7,387$ ), followed by moving $17.9 \%(3,261)$, standing $10.1 \%(1,849)$, resting $23.5 \%(4,281)$, vigilance $1.6 \%$ (289), social activity $2.1 \%$ (379), rutting $2.37 \%$ (414) and other activities $2.1 \%$ (376). We observed slight changes in activity patterns between wet and dry seasons $\left(\mathrm{F}_{7,18228}=27.88\right.$, $\mathrm{df}=7, \mathrm{p}<0.01$ ) (Fig. 2). We observed more rutting, feeding, and resting during the dry season, and more moving activity during the wet season, although all activities varied less than $5 \%$ in absolute different between wet and dry seasons.

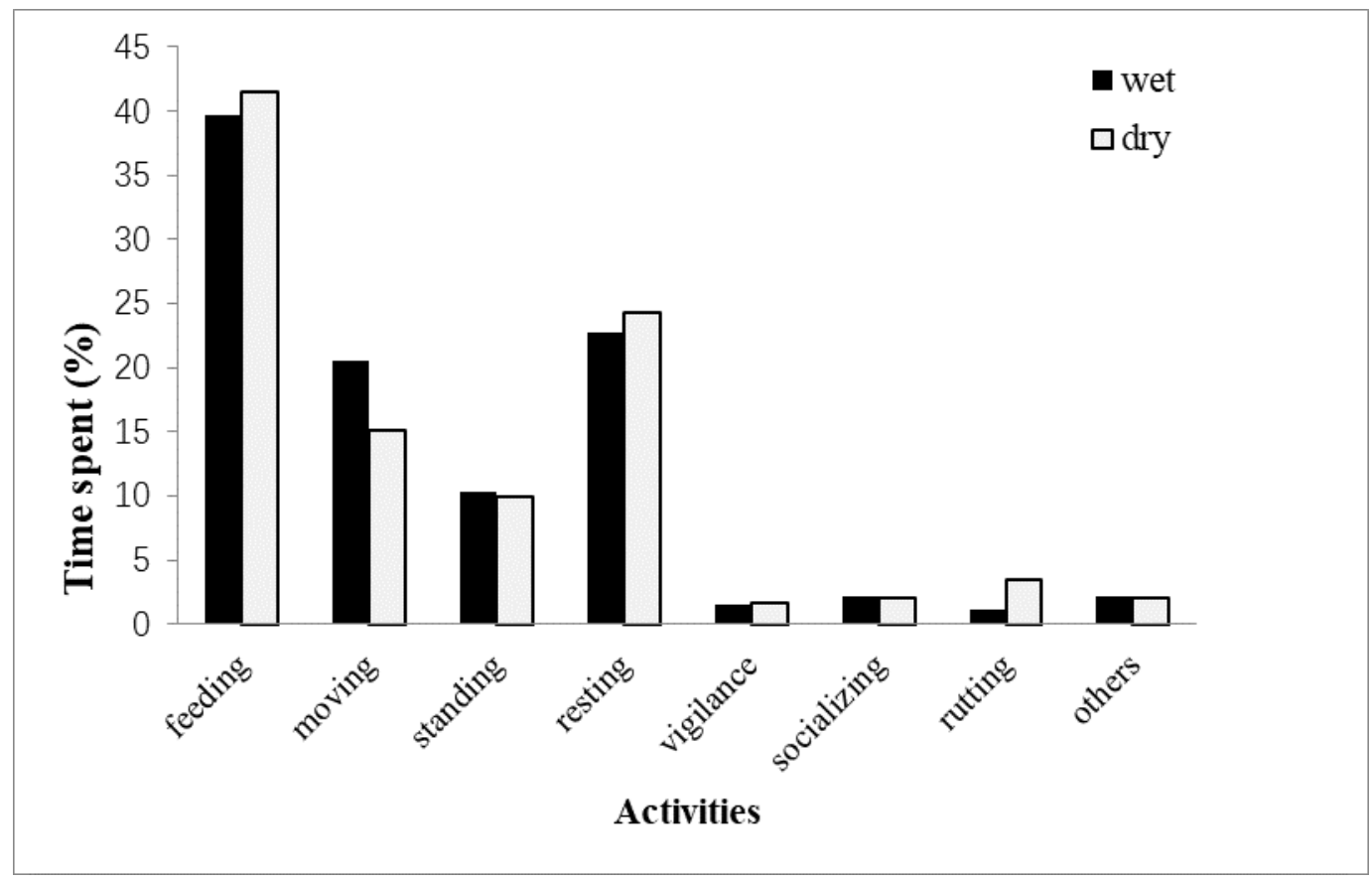

Figure 2. Percentage of time spent for different diurnal activities by walia ibex during the wet and dry seasons

Daily activity patterns of walia ibex followed the expected crepuscular patterns; ibex spent more time feeding during the early morning and afternoon, while resting increased during mid-day (Fig. 3). 


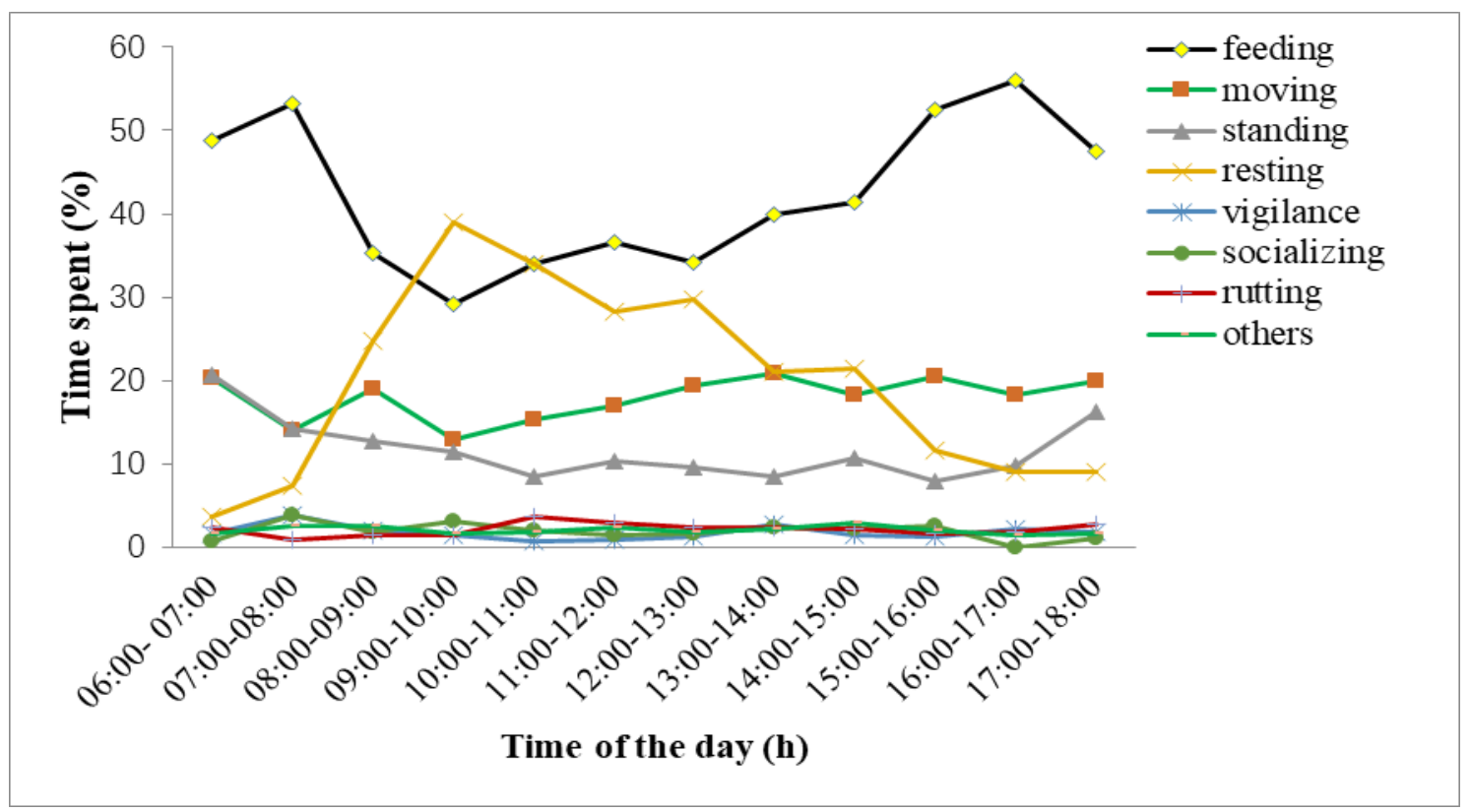

Figure 3. Daily percentage activities of walia ibex during the study period

Feeding, moving, and resting activity did not vary between wet and dry seasons (feeding: $\chi^{2}=$ $0.01, \mathrm{df}=1, \mathrm{p}>0.05$; moving: $\chi^{2}=0.71, \mathrm{df}=1, \mathrm{p}>0.05$; resting: $\chi^{2}=0.02, \mathrm{df}=1, \mathrm{p}>0.05$ ). Feeding activities in walia ibex during the wet and dry seasons declined shortly during 08:00 - 10:00 $\mathrm{h}$ and increased after 10:00 h, reaching its peak in the late afternoon (Fig. 4). Resting activity increased before noon during both wet and dry seasons.

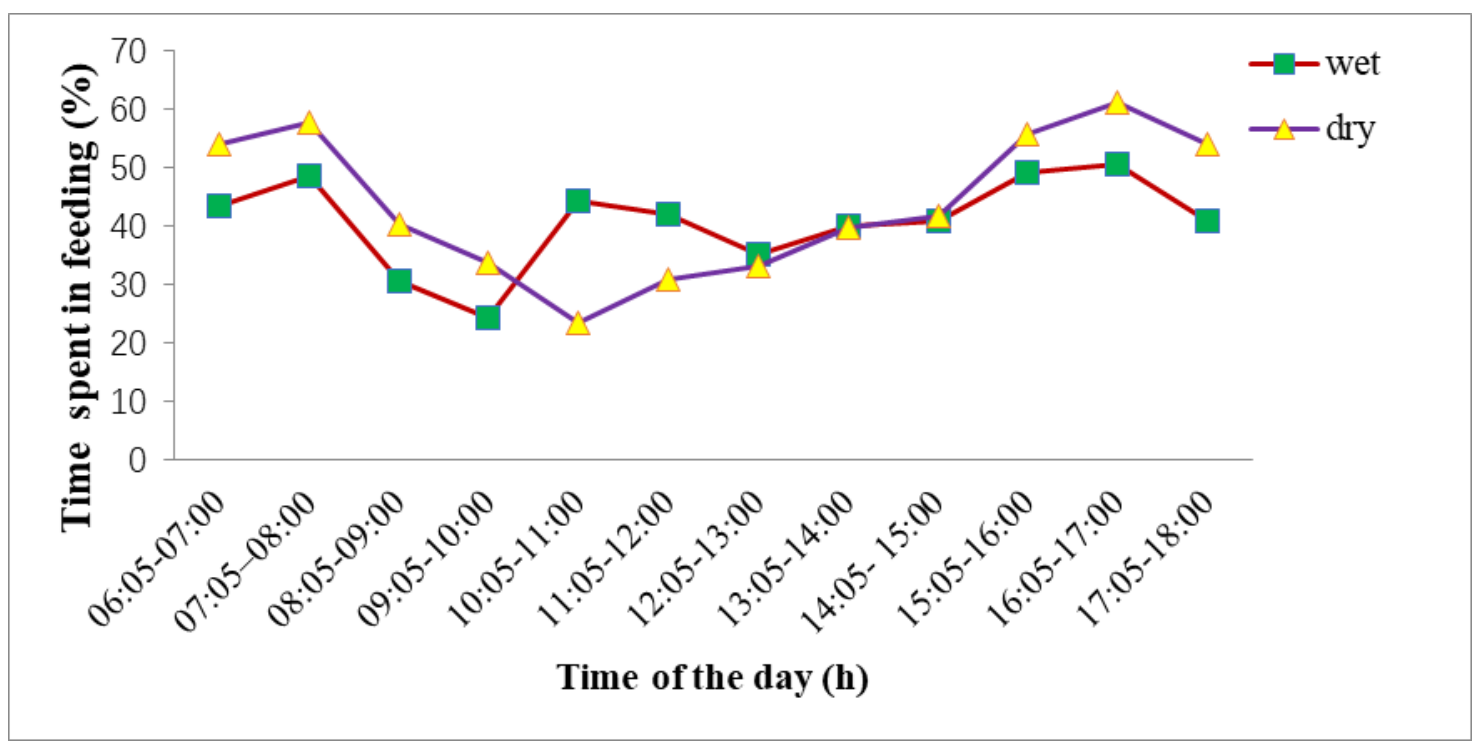

Figure 4. Percentage of time spent in feeding by walia ibex during the wet and dry seasons

We observed a difference in daily rutting activity patterns between wet and dry seasons $\left(\chi^{2}=\right.$ 4.6; $\mathrm{df}=1 ; \mathrm{p}<0.05)$. Walia ibex exhibited a fairly constant, low level of rutting $(<2 \%$ of time period) during the wet season. During the dry season, rutting activity increased substantially late in the morning and slowly declined in the afternoon, and then increased in the evening (Fig.5). 


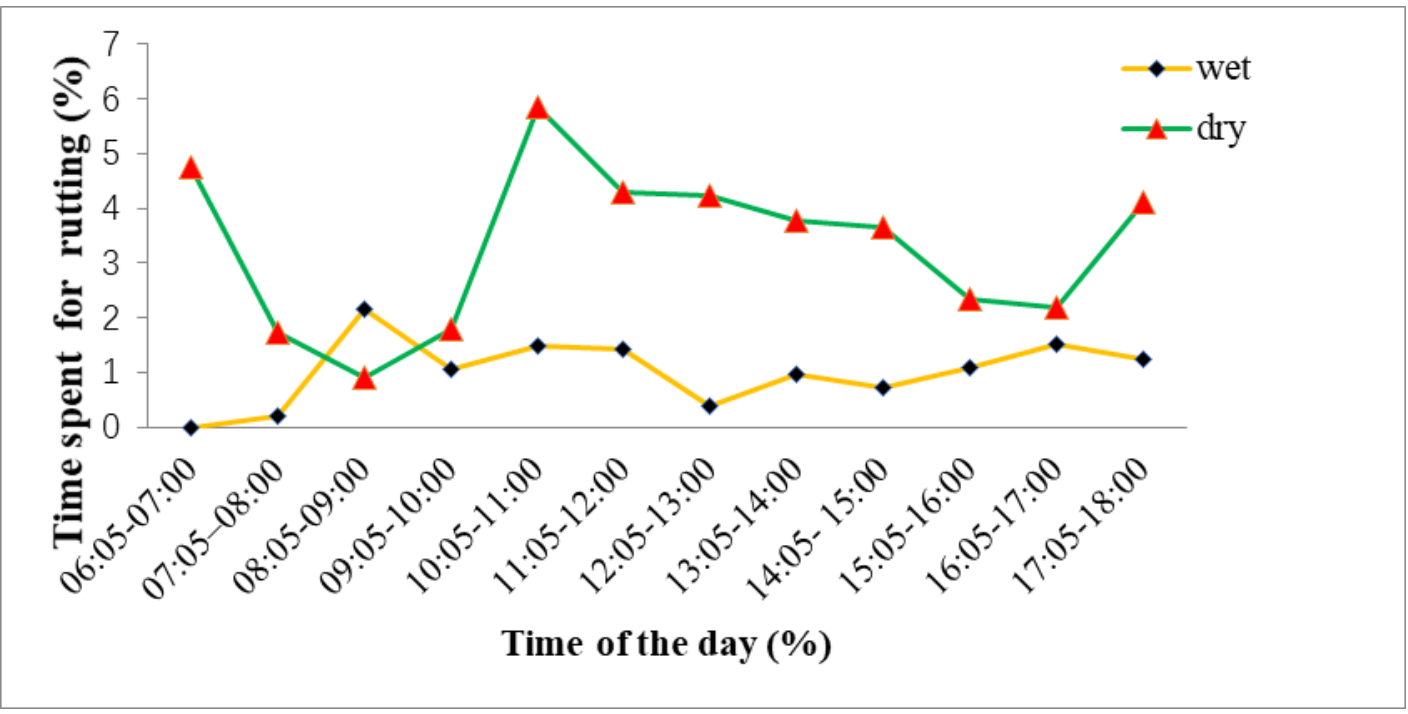

Figure 5. Percentage of time spent in rutting by walia ibex during the wet and dry seasons

We observed small differences in the diurnal activities for adult females $\left(\mathrm{F}_{7,6163}=7.57, \mathrm{df}=7\right.$, $\mathrm{p}<0.01$ ). Females in walia ibex spent most of their time feeding (wet: $46.2 \%, \mathrm{n}=1480$; dry: $44.3 \%, 1311)$, followed by moving $(19.1 \%, 611 ; 15.0 \%, 445)$, standing $(9.8 \%, 314 ; 11.9 \%$, $353)$, resting $(20.5 \%, 657 ; 21.9 \%, 648)$, vigilance $(1.8 \%, 59 ; 2.8 \%, 82)$, social activities $(0.3 \%, 9,0.5 \%, 14)$, rutting $0.8 \%, 26 ; 2.3 \%, 67)$, and other activities $(1.6 \%, 51 ; 1.5 \%, 43)$. We observed similar difference in male walia ibex activity between wet and dry seasons $\left(\mathrm{F}_{7,6462}=25.59, \mathrm{df}=7, \mathrm{p}<0.01\right)$. Males spent less of their day feeding than females, but feeding was the most frequent activity (wet: $33.0 \%, \mathrm{n}=1076$; dry $35.3 \%, \mathrm{n}=1133$ ), followed by moving $(18.2 \%, 594 ; 11.3 \%, 363)$, standing $(11.2 \%, 364 ; 7.0 \%, 223)$, resting $(30.3 \%, 988$; $34.5 \%, 1107)$, vigilance $(1.8 \%, 57 ; 1.2 \%, 38)$, social activities $(1.4 \%, 46 ; 2.0 \%, 64)$, rutting $(2.3 \%, 74 ; 6.8 \%, 217)$, and other activities $(1.6 \%, 51 ; 2.0 \%, 64)$

\section{Discussion}

Diurnal activity patterns in walia ibex showed that percentage of time spent feeding was the highest while vigilance was the lowest. This result is consistent with previous results conducted on feral goats (Stronge et al., 1997). This indicated that though intense human and livestock disturbances were common in habitats of walia ibex, they might have developed behavioral adaptation and became less vigilant to people and livestock available even at close proximity (Ejigu, 2013). This kind of adaptation might be an indication for the absence of predators as well as poaching in the area. Vigilance in ungulates is considered to have a predominantly antipredator function and changes in its behavior have usually been attributed to variation in predation risk (Cameron \& Dutoit, 2005). We noticed that walia ibex became more vigilant in areas where they did not commonly encounter human disturbance in the remote parts of the SMNP especially closer to gorges and escarpments. Ibex use alarm calls to alert others to the presence of potential predators (Accevedo \& Cassinello, 2009), and we noted that alarm calls were also common in walia ibex population as they encountered intruders.

Diurnal activity patterns with high levels of feeding activity in the morning and afternoon and 
resting in mid-day were expected. However, the analysis indicated that feeding behavior in walia ibex remained the same throughout the year, which is likely because variation in temperature between seasons is minimal (Nievergelt, 1981, 1990). However, others have reported increased in feeding time with decreasing food availability during the dry season has been observed for several African grazers (Own-Smith, 1982). Perhaps food availability was not limiting in the SMNP for walia ibex in our study. The availability of fresh and palatable grass during the wet season might explain the small differences we observed in feeding activity between seasons. During the wet season, time spent feeding was shorter and could easily be interrupted before noon, while during the dry season, relatively more time was spent feeding and searching for forage before noon.

Rutting activity in walia ibex was displayed smoothly throughout the day during the wet season regardless of slight variations occurred late in the morning. During the dry season, it fluctuated and then increased starting from late in the morning to noon. Thus, there was significant difference in time spent rutting between the wet and dry seasons. This indicated that even though walia ibex showed rutting behavior throughout the year, it showed stronger peaks during the dry season than the wet season. Adult walia ibex have a significantly more pronounced rutting peak from March to May (Nievergelt, 1981). This indicated that even slight variation in temperature between seasons in SMNP might stimulate adult walia ibex to become more active for rutting during the dry season than the wet season. Although a small portion of the day was spent in rutting, knowledge of the pattern of this behavior can be especially useful to conservation planning as successful reproduction in the population may be threatened by anthropogenic disturbances.

Adult females require $>10 \%$ more time feeding than adult males in both wet and dry seasons, which is also true in feral goats (Stronge et al., 1997) and bighorn sheep (Ruckstuhl, 1998). Male ungulates require lower diet and habitat quality than females (Mysterud, 2000). Moreover, females should select habitats that maximize the ability to raise young since this limits their reproductive success (Mysterud, 2000; Ruckstuhl \& Neuhaus, 2002; Accevedo \& Cassinello, 2009). In spite of differences in their body size between adult females and adult males, the former required more time feeding than the latter. This might be because adult females required additional energy needed for gestation and lactation. Differences in diet are more pronounced in dimorphic ungulates (Stronge et al., 1997). In Alpine ibex, for example, adult males spent only $8.5 \%$ of the time feeding, and it is likely that they compensate such reduced feeding times by foraging at night (Neuhaus \& Ruckstuhl, 2002). The same scenario was also observed in walia ibex at SMNP, where adult males were reported to feed at night including crop raiding that led to complaints and observations by local farmers. But, during the day, adult males spent relatively more time resting than adult females as expected (Stronge et al., 1997). Though defecation and urination are important physiological parameters such activities together with other rarely occurring ones are recorded as other activities and time spent for such activities is not as such significant compared to time spent for other diurnal activities. 
As conservation plans are modified for walia ibex in the SMNP, the knowledge of activity patterns will be useful. Our study suggests that seasonal differences in activity patterns are minimal for males and females in the park, which is likely a consequence of local resource availability and disturbance levels. Hence, understanding the diurnal activity patterns of walia ibex might be useful to monitor the effects of human activity and resource abundance for sustainable conservation of walia ibex in the future.

\section{Conflict of interest}

The authors declare no conflict of interest.

\section{Acknowledgements}

We thank the field assistants and park scouts in the SMNP for their great help during data collection period. The first author is greatly indebting to Bahir Dar University, Addis Ababa University, CEPA, the Mohamed bin Zayed Species Conservation Fund, Chicago Zoological Society, and Lleida University for providing research fund.

\section{References}

Accevedo, P., \& Cassinello, J. (2009). Biology, ecology and status of Iberian ibex (Capra pyrenaica): a critical review and research prospectus. Mamm. Rev., 39, 17-32. https://doi.org/10.1111/j.1365-2907.2008.00138.x

Altman, J. (1974). Observational study of behaviour: sampling methods. Behavior, 49, 227-267. https://doi.org/10.1163/156853974X00534

Anonymous (2009). Simien Mountains National Park General Management Plan. AmharaNational Regional State Parks Development and Protection Authority. Bahir Dar.

Apio, A., \& Wronski, T. (2005). Foraging behaviour and diet composition of bushbuck (Tragelaphus scriptus Pallas, 1766) in Queen Elizabet National Park, western Uganda. Afr. J. Ecol., 43, 225-232. https://doi.org/10.1111/j.1365-2028.2005.00576.x

Beale, C., \& Monaghan, P. (2004). Behavioural responses to human disturbance: a matter of choice. Anim. Behav., 68, 1065-1069. https://doi.org/10.1016/j.anbehav.2004.07.002

Belovsky, G. E., \& Slade, J. B. (1986). Time budgets of grassland herbivorous: body size similarities. Oecologia, 70, 53-62. https://doi.org/10.1007/BF00377110

Bocian, C. M. (1997). Niche Separation of Black and White Colobus Monkeys (Colobus angolensis and C. guereza) in the Ituri Forest. PhD Dissertation. The City University of New York, New York.

Cameron, E. Z., \& Dutoit, J. (2005). Social influences on vigilance behaviour in giraffes (Giraffa camelopardalis). Anim. Behav., $\quad 69, \quad$ 1337-1344. https://doi.org/10.1016/j.anbehav.2004.08.015 
Dunbar, R. I. M. (1978). Competition and niche separation in a high altitude of herbivore community in Ethiopia. Afr. J. Ecol. 16, 183-199. https://doi.org/10.1111/j.1365-2028.1978.tb00439.x

Dunbar, R. I. M., \& Dunbar, E. P. (1981). The grouping behaviour of male walia ibex with special reference to the rut. Afr. J. Ecol., 19, 251-263. https://doi.org/10.1111/j.1365-2028.1981.tb01063.x

Ejigu, D. (2013). Population status and ecology of walia ibex (Capra walie): A study to address its conservation in Simien Mountains National Park, Ethiopia. PhD Dissertation, Addis Ababa University, Ethiopia.

Ejigu, D., Bekele, A., Powell, L., \& Lenould, J. M. (2015). Habitat preference of the endangered Ethiopian walia ibex (Capra walie) in the Simien Mountains National Park, Ethiopia. Animal Biodivers. \& Conserverv., 38(1), 1-10.

Falch, F., \& Keiner, M. (2000). Simien Mountains National Park General Management Plan. Amhara National Regional State, Bahir Dar.

Hess, R. (2002). The Ecological Niche of Markhor (Capra falconeri) between Wild goat (Capra aegagrus) and Asiatic ibex (Capra ibex) PhD Dissertation, Nat University, Zurich.

Hochman, V., \& Kotler, B. P. (2006). Patch use, apprehensive and vigilance behaviour of Nubian ibex under perceived risk of predation. Behav. Ecol., 5, 1-7.

Hurni, H. (1982). Simien Mountains, Ethiopia: Climate and the Dynamics of Altitudinal Belts from the Last Cold Period to the Present Day. Geographica Bernensia, Berene.

Hurni, H., \& Ludi, E. (2000). Reconciling Conservation with Sustainable Development. A participatory Study Inside and Around the Simien Mountains National Park. Center for Development and Environment (CDE), University of Berne, Berne.

Krausman, P. R., \& Morrison, M. L. (2003). Wildlife Ecology and Management, Santa Rita Experimental Range (1903 to 2002). USDA Forest Service Proceedings RMRS-P-30, Tucson, Arizona.

Massicot, P. (2001). Animal Info-waliaibex (on-line) at http://www.animalinfo.org/caprawalie.htm (Accessed on 4, May 2018).

Mobaek, R., Narmo, A. K., \& Moe, S. R. (2005). Termitaria are focal feeding sites for large ungulates in Lake Mburo National Park, Uganda. J. Zool. Lond., 267, 97-102. https://doi.org/10.1017/S0952836905007272

Mysterud, A. (2000). The relationship between ecological segregation and sexual body size dimorphism in large herbivores. Oecologia, 124, 40-54. https://doi.org/10.1007/s004420050023

Nievergelt, B. (1981). Ibexes in an African Environment. Ecology and Social Systems of the Walia ibex in the Simien Mountains National Park, Ethiopia. Springger-Verlag, Berlin. https://doi.org/10.1007/978-3-642-67958-2 


\section{Macrothink

Nievergelt, B. (1990). Ethiopian ibex or walia ibex. In: Parker, pp 523-525, (S.P ed.). Grzimek's Encyclopedia of mammals, Volume 5. McGraw-Hill, New York.

Owen-Smith, N. (1982). Factors influencing the consumption of plant products by large herbivoros. In: Ecology of Tropical Savannas, pp 359-404, (Huntley, B.J. and Walker, B.H., eds.), Springer-Verlag, Berlin. https://doi.org/10.1007/978-3-642-68786-0_17

Puff, C., \& Nemomissa, S. (2001). The Simien Mountains (Ethiopia): comments on plant biodiversity, endemism, phytogeographical affinities and historical aspects. Syst. Geogr. Pl., 71, 975-991. https://doi.org/10.2307/3668732

Puff, C., \& Nemomissa, S. (2005). Plants of Simien. A flora of the Simien Mountains and Surroundings, Northern Ethiopia. Meise, National Botanic Garden of Belgium, Brussels.

Ruckstuhl, K. E. (1998). Foraging behaviour and segregation in bighorn sheep. Anim. Behav., 56, 99-106. https://doi.org/10.1006/anbe.1998.0745

Ruckstuhl, K. E., \& Neuhaus, P. (2002). Sexual segregation in ungulates: a comparative test of three hypotheses. Biol. Rev., 77, 77-96. https://doi.org/10.1017/S1464793101005814

Senft, R. L., Coughenour, M. B., Bailey, D. W., Rittenhouse, L. R., Sala, O. E., \& Swift, D. M. (1987). Large herbivore foraging and ecological hierarchies. Bio. Sci., 37, 789-799. https://doi.org/10.2307/1310545

Shorrocks, B., \& Cokayne, A. (2005). Vigilance and group size in impala (Aepyceros melampus): A study in Nairobi National Park, Kenya. Afr. J. Ecol., 43, 91-96. https://doi.org/10.1111/j.1365-2028.2005.00541.x

Stronge, D. C., Fordham, R. A., \& Minot, E. (1997). The foraging ecology of feral goats (Capra hircus) in the Mahoenui Giant Weta Reserve, southern King County, New Zealand. New Zeal. J. Ecol., 21, 81-88.

Vinod, T. R., \& Sathyakumar, S. (1999). Ecology and Conservation of Mountain Ungulates in Great Himalayan National Park, Western Himalaya Wildlife Institute of India, Chandrabani, Dehra Dun - 248 001, U.P., India.

\section{Copyright Disclaimer}

Copyright for this article is retained by the author(s), with first publication rights granted to the journal.

This is an open-access article distributed under the terms and conditions of the Creative Commons Attribution license (http://creativecommons.org/licenses/by/4.0/). 